\title{
Ekstraksi Citra Fitur Pada Pengenalan Pola Motif Batik Sleman Menggunakan Metode Gray Level Co-Occurrence Matrix
}

\author{
Marwan Noor Fauzy ${ }^{1)}$, Bambang Soedijono ${ }^{2)}$, Sudarmawan ${ }^{3)}$ \\ ${ }^{123}$ Program Pascasarjana Magister Teknik Informatika Univeritas Amikom Yogyakarta \\ ${ }^{123} \mathrm{Jl}$. Ringroad Utara, Condong Catur, Sleman, Yogyakarta, Telp/Fax (0274) 884201 - 207 \\ 1'marwanfzy@gmail.com, ${ }^{2}$ bambang.s@amikom.ac.id, ${ }^{3}$ sudarmawan@amikom.ac.id
}

\begin{abstract}
Abstrak
Batik merupakan bagian dari keragaman budaya turun temurun yang harus kita jaga dan dilestarikan karena batik merupakan bagian dari warisan dunia dan telah diakui oleh UNESCO. Tradisi batik sudah menjadi identitas indonesia yang terkenal tidak hanya di kalangan masyarakat namun sudah dikenal di luar negeri. Identifikasi motif batik secara pengelihatan diperlukan pengetahuan yang cukup dengan memperhatikan pola yang terbentuk dari motif batik tersebut. pola dari setiap motif batik memiliki ciri khas tersendiri namun karena kurangnya pemahaman, ilmu serta informasi tentang motif matik sehingga masyarakat luas mengalami kesulitan dalam mengenali dan mengklasifikasi motif batik. Algoritma GLCM merupakan salah satu metode dalam pengenalan pola, Metode ini merupakan matriks yang terbentuk berdasarkan citra grayscale dan matriks ini menghitung frekuensi kemunculan suatu nilai piksel horizontal terhadap piksel vertikal yang bersebelahan maupun secara diagonal. Pada penelitian ini menggunakan data gambar berjumlah 30 citra pada 3 motif batik, yaitu motif parijotho, motif salak pondoh dan motif belut dan salak. aplikasi matlab R2016a dan menghasilkan proses ekstraksi fitur dan digunakan sebagai data dari pengenalan pola yaitu pada fitur energy, correlation, homogenity dan contrast.
\end{abstract}

Kata kunci:batik, ekstraksi fitur, gray level co-occurrance matrix

\section{PENDAHULUAN}

Menurut Djoemena, Batik adalah seni kreasi membuat bahan sandang dengan motif-motif hias menggu -nakan media malam/ wax di atas bahan kain (Djoemena, 1990). Keanekaraman motif batik di indonesia memiliki jumlah yang banyak sehingga banyak orang yang mengalami kesulitan dalam proses identifikasi antara motif satu dengan motif yang lainnya.

Untuk melestarikan kekayaan budaya, Kabupaten Sleman memiliki beberapa batik khas, diantaranya motif sinom parojotho, motif salak pondoh dan motif belut dan salak. Seperti halnya batik dari berbagai daerah lainnya di Indoensia wajib memiliki karakteristik, oleh karena itu batik khas Sleman juga memiliki karakteristik yang dapat dilihat dari motif desainnya, yang terinspirasi dari keberagaman tumbuhan dan hewan khas dari kabupaten sleman serta kondisi geografis di Kabupaten Sleman.

Pengenalan pola dapat diterapkan pada pengenalan motif batik yaitu dengan mengimplementasikan ekstraksi fitur tekstur (P. Ashok, 2012). Dalam proses klasifikasi motif batik diperlukan pengenalan pola yaitu sebuah disiplin ilmu untuk mengklasifikasikan atau menggambarkan sesuatu berdasarkan pengukuran kuantitatif fitur (ciri) atau sifat utama dari suatu obyek (Putra, 2010).

Namun karena kurangnya pemahaman tentang motif batik khas sleman sehingga masyarakat mengalami kesulitan dalam mengenalinya.

Penelitian ini bertujuan untuk pengenalan pola dalam mengklasifikasi citra digital fitur tekstur pada motif batik khas Sleman menggunakan algoritma Gray Level Co-Occurrence Matrix (GLCM), fitur-fitur yang digunakan adalah energy, correlation, homogenity dan contrast.

\section{METODE PENELITIAN}

Dalam menyelesaikan penelitian, dilakukan secara sistematis, dengan tahapantahapan metodologi sebagai berikut:
a. Studi Pustaka
Penelitian dilakukan dengan melakukan studi kepustakaan, dengan mengumpulkan 
beberapa bahan referensi yang terkait dengan penelitian, baik melalui buku, artikel paper, jurnal, makalah, dan mengunjungi beberapa situs yang terdapat di initernet terait dengan pengenalan pola khususnya algoritma yang dapat mengklasifikasi citra pada motif batik

\section{b. Persiapan alat dan bahan}

Tahapan ini melakukan persiapan tools yang digunakan dalam melakukan analisis pendeteksi pemalsuan image menggunakan MATLAB. Image yang digunakan didapat dari website serta mengambil gambar dari kamera smartphone dan membuat dataset sendiri menggunakan aplikasi Adobe Photoshop.

\section{c. Pengembangan Sistem}

Membangun sistem untuk klasifikasi motif batik menggunakan algoritma GLCM, dengan mencari nilai kemiripan citra yang didapat pada image yang di analisis seperti yang ditunjukan pada tabel nomor 1 dibawah.

Tabel 1. Proses Ekstraksi Image

\begin{tabular}{|c|c|c|}
\hline Image & Ekstraksi & Konversi \\
\hline & & \begin{tabular}{|l|l|l|l|l}
2 & 1 & 2 & 0 & 1 \\
0 & 2 & 1 & 1 & 2 \\
0 & 1 & 2 & 2 & 0 \\
1 & 2 & 2 & 0 & 1 \\
2 & 0 & 1 & 0 & 1 \\
\end{tabular} \\
\hline & & \begin{tabular}{|l|l|l|l|l|}
2 & 1 & 2 & 0 & 1 \\
0 & 2 & 1 & 1 & 2 \\
0 & 1 & 2 & 2 & 0 \\
1 & 2 & 2 & 0 & 1 \\
2 & 0 & 1 & 0 & 1 \\
\end{tabular} \\
\hline & & \begin{tabular}{|l|l|l|l|l}
2 & 1 & 2 & 0 & 1 \\
0 & 2 & 1 & 1 & 2 \\
0 & 1 & 2 & 2 & 0 \\
1 & 2 & 2 & 0 & 1 \\
2 & 0 & 1 & 0 & 1 \\
\end{tabular} \\
\hline
\end{tabular}

\section{d. Kesimpulan}

Tahapan akhir yaitu penyampaian kesimpulan atas hasil dari penelitian ini.

\section{TINJAUAN PUSTAKA}

a. Gray Level Co-occurrance Matrix

Gray Level Co-Occurrence Matrix (GLCM) merupakan suatu citra sebagai distribusi dari saling-kemunculan (cooccurrence) nilai piksel pada area tertentu, atau mewakili hubungan spasial sudut dan jarak pada area tertentu dan dengan ukuran tertentu (Arnia \& Munadi, 2018).

Metode ini biasanya digunakan dalam pengenalan tekstur, segmentasi citra, analisis warna pada citra, klasifikasi citra, dan pengenalan objek (Ch B Nageswara Rao, 2013).

Komponen utama dalam GLCM adalah arah dan jarak antara dua piksel. Arah ketetanggaan yang mungkin antara dua buah piksel adalah $0^{0}, 45^{\circ}, 90^{\circ}, 135^{\circ}$, $180^{\circ}, 225^{\circ}, 270^{\circ}$, dan $315^{\circ}$ seperti pada gambar 1 dibawah ini.

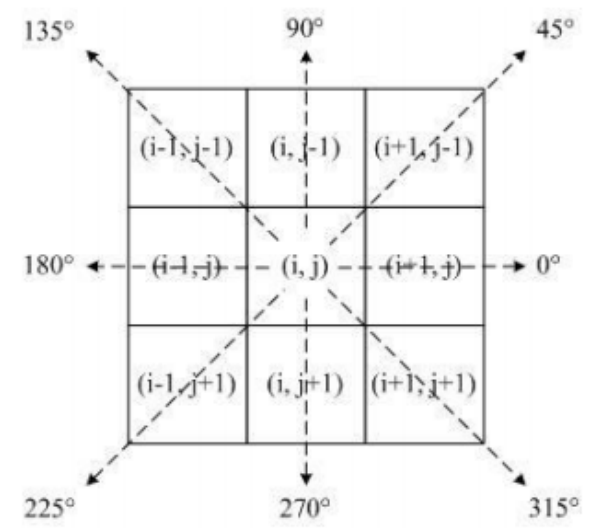

Gambar 1. Arah ketetanggaan

Langkah selanjutnya setelah proses normalisasi dilakukan adalah menghitung ciri atau fitur statistik GLCM. Beberapa ciri atau fitur statistik yang akan digunakan dalam penelitian ini adalah sebagai berikut :

a. Energy

Energy digunakan untuk mengukur homogenitas sebuah citra, Dimana P_(i,j) menyatakan nilai pada baris $\mathrm{i}$ dan kolom $\mathrm{j}$ pada matriks kookurensi.

$$
\text { Energy }=\sum_{i=0}^{G-1} \sum_{j=0}^{G-1} P_{i, j}{ }^{2}
$$

\section{b. Correlation}

Correlation digunakan untuk menghitung keterkaitan piksel yang memiliki level keabuan i dengan piksel yang memiliki level keabuan $\mathrm{j}$.

$$
=\sum_{i=0}^{\substack{\text { Correlation } \\ G-1}} \sum_{j=0}^{G-1} \frac{\left(i-\mu_{i}\right)\left(j-\mu_{j}\right)}{\sigma_{i} \sigma_{j}} P_{i, j}
$$

\section{c. Homogenity}

Homogenity atau Inverse Different Moment (IDM) digunakan untuk mengukur homogenitas citra dengan level keabuan sejenis. 


$$
\text { Homogenity }=\sum_{i=0}^{G-1} \sum_{j=0}^{G-1} \frac{1}{1+(i-j)^{2}} P_{i, j}
$$

\section{d. Contrast}

Contrast digunakan untuk mengukur variasi pasangan tingkat keabuan dalam sebuah citra.

$$
\text { Contrast }=\sum_{i=0}^{G-1} \sum_{j=0}^{G-1}(i-j)^{2} P_{i, j}
$$

\section{HASIL DAN PEMBAHASAN}

Pada penelitian ini pengumpulan data dilakukan secara langsung yaitu dengan mengambil gambar motif batik menggunakan smartphone. Data motif batik terdiri dari 3 ragam motif batik yaitu motif sinom parojotho, motif salak pondoh dan motif belut dan salak. Total dataset yang telah dikumpulkan adalah 30 citra gambar dengan rincian pada setiap motif batik berjumlah 10 citra gambar.

Proses selanjutnya adalah ekstraksi fitur menggunakan algoritma GLCM. Ekstraksi fitur ini menghasilkan nilai nilai fitur citra yang berbeda pada setiap pola motif batik. Fitur yang diekstrak dari setiap motif batik adalah fitur energy, correlation, homogenity dan contrast.

Pengolahan ekstraksi citra pada tahapan pre-processing merupakan proses cropping image, resize image dan mengubah image tersebut menjadi grayscale. Hasil dari preprocessing image yaitu memotong dan mengecilkan gambar menjadi image dengan resolusi 100x100 piksel dengan tujuan untuk memudahkan proses ekstraksi fitur. Kemudian proses selanjutnya mengubah image menjadi grayscale menggunakan aplikasi photoshop, sehingga menghasilkan hasil konversi seperti gambar 2.
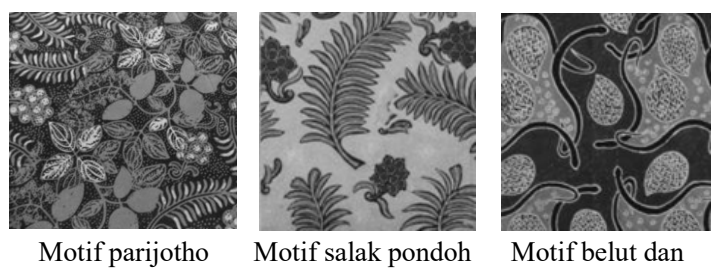

Motif salak pondoh

Motif belut dan salak

Gambar 2. Tahapan Pre-processing

Hasil yang diperoleh pada penelitian ini adalah proses ekstraksi fitur dengan metode GLCM pada pengenalan motif batik khas kabupaten sleman. Proses ekstraksi tersebut menggunakan $8 \times 8$ offset GLCM pada arah horizontal ([0, 1]) dengan keterangan memiliki jarak 1 piksel dengan sudut orientasi $0^{0}$ menggunakan aplikasi matlab sehingga menghasilkan nilai ekstraksi fitur seperti pada tabel 2 dibawah.

Tabel 2. Hasil ekstraksi image

\begin{tabular}{ccccc}
\hline Motif & energy & $\begin{array}{c}\text { correl } \\
\text { ation }\end{array}$ & $\begin{array}{c}\text { Hom } \\
o \\
\text { genit } \\
\text { contras }\end{array}$ & $\begin{array}{c}t \\
\text { con }\end{array}$ \\
\hline $\begin{array}{c}\text { Parijot } \\
\text { ho }\end{array}$ & 2,832 & 5,637 & 1,323 & 3,674 \\
$\begin{array}{c}\text { Salak } \\
\text { pondo } \\
\text { h }\end{array}$ & 2,367 & 6,032 & 0,92 & 4,193 \\
$\begin{array}{c}\text { Belut } \\
\text { dan } \\
\text { salak }\end{array}$ & 2,564 & 6,177 & 0,83 & 3,531 \\
\hline
\end{tabular}

Dari pengujian terhadap 10 gambar pada setiap motif batik menghasilkan grafik seperti pada gambar 3 sampai 6 pada setiap ekstraksi fitur.

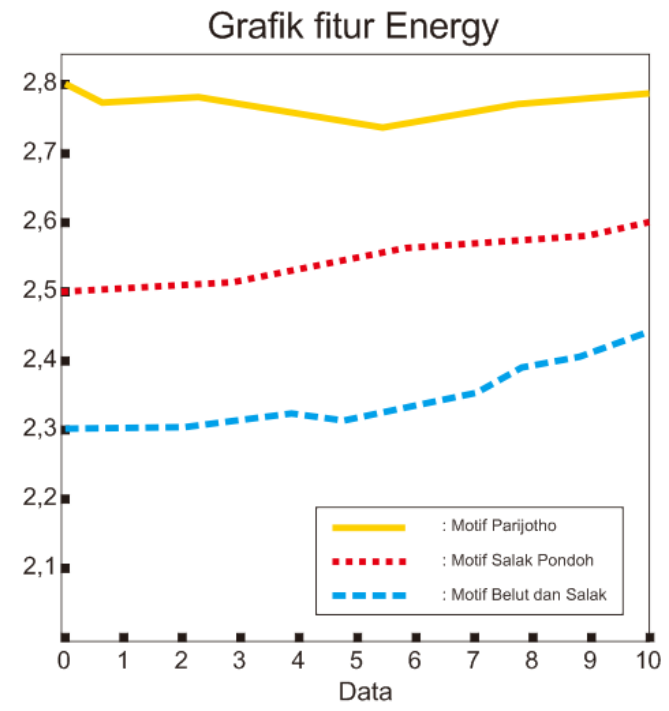

Gambar 3. Grafik fitur energy 


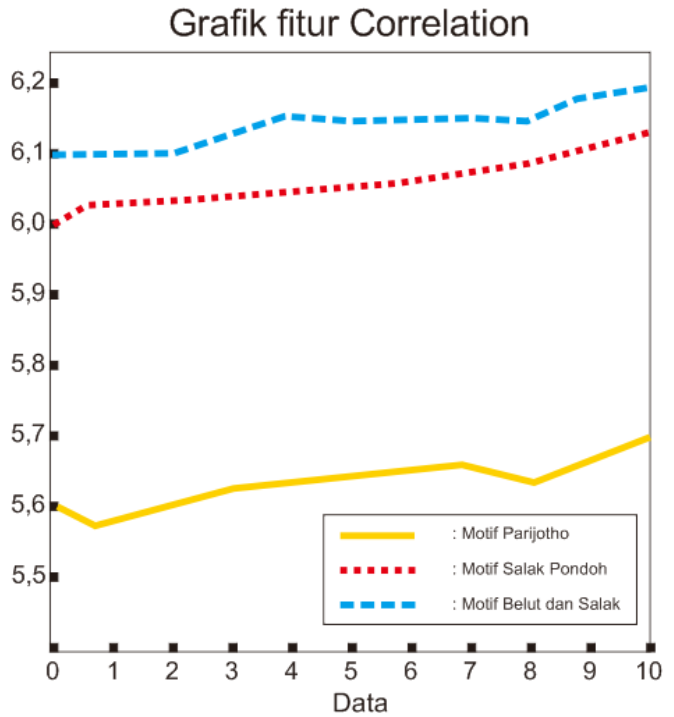

Gambar 4. Grafik fitur Correlation Grafik fitur Homogenity

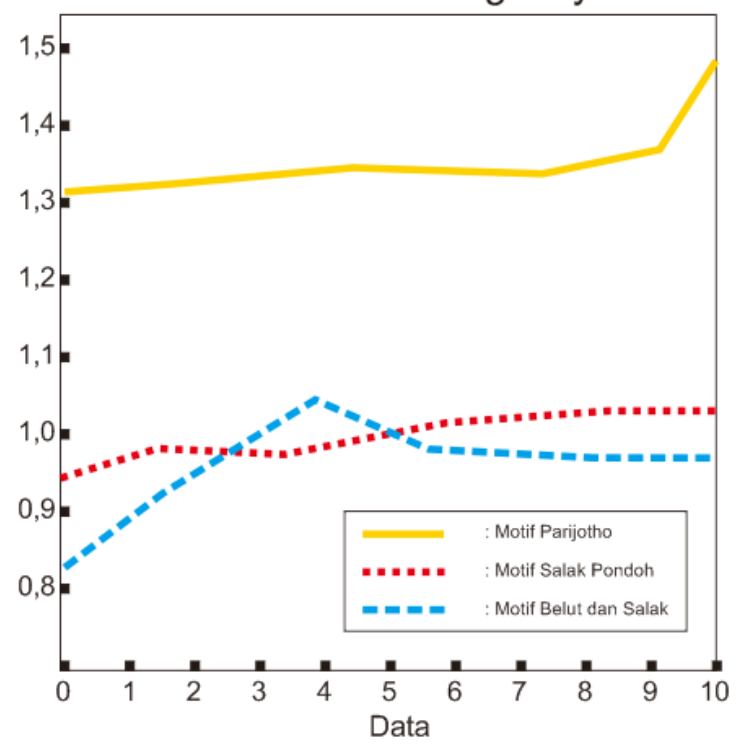

Gambar 5. Grafik fitur Homogenity Grafik fitur Contrast

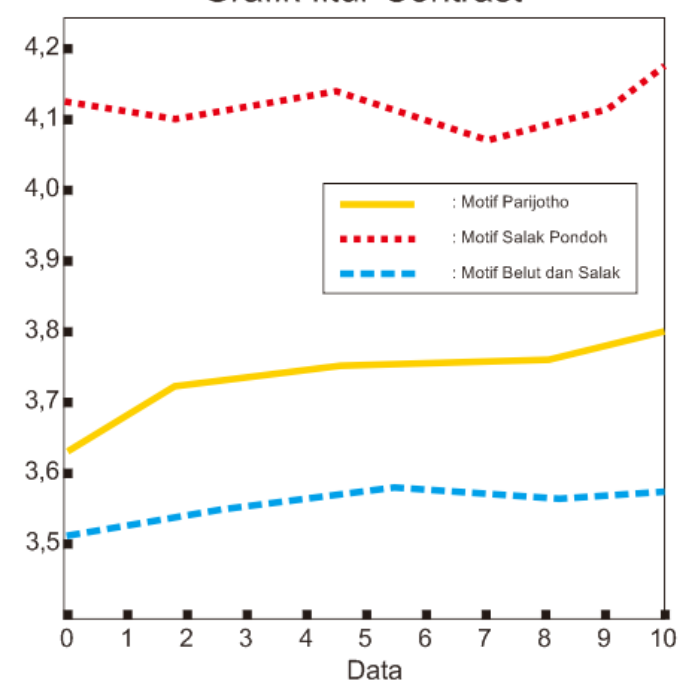

Gambar 6. Grafik fitur Contrast
Pada tabel 2 dan gambar-gambar grafik diatas menjuntukan bahwa ekstraksi fitur GLCM dapat membedakan motif-motif batik, pada ekstraksi fitur energy, corelation, homogenity dan contrast dapat digunakan untuk mengenali pola dari motif batik khas sleman.

\section{KESIMPULAN DAN SARAN \\ a. Kesimpulan}

Pada penelitian ini menghasilkan datadata yang diperoleh dari proses ekstraksi fitur dengan menggunakan algoritma GLCM dan data yang diperoleh telah dibuatkan grafik sehingga dapat membedakan nilai ekstraksi fitur dan dapat mengenali pola pada setiap motif batik.

\section{b. Saran}

Saran untuk pengembangan pada penelitian selanjutnya dapat gabungkan dengan learning machine sehingga dapat menghasilkan sistem penunjang keputusan dalam pengenalan pola motif batik.

\section{REFERENSI}

Arnia F., Munadi, K, 2018, Pengantar Teknik Pengolahan Citra dan Visi Komputer, Penerbit Ombak, Yogyakarta.

Rao, C.N., Sastry, S.S., Mallika, K., Tiong, H.S. \& Mahalakshmi, K.B, 2013, Co-occurrence matrix and its statistical features as an approach for identification of phase transitions of mesogens, International Journal of Innovative Researchin Science, Engineering and Technology 2: 45314538.

Babu, P. Ashok. 2012. Texture Segmentation by Using Haar Wavelets and Kmeans Algorithm. Associate Professor, Narsimha Reddy Engineering College, Hyderabad, A.P., INDIA. Online, Volume 1.

Putra, Darma, 2010. Pengolahan Citra Digital, CV. Andi Offset, Yogyakarta

Djoemena, Nian S. (1990), Ungkapan Sehelai Batik: Its Mystery and Meaning, Djambatan, Jakarta. 